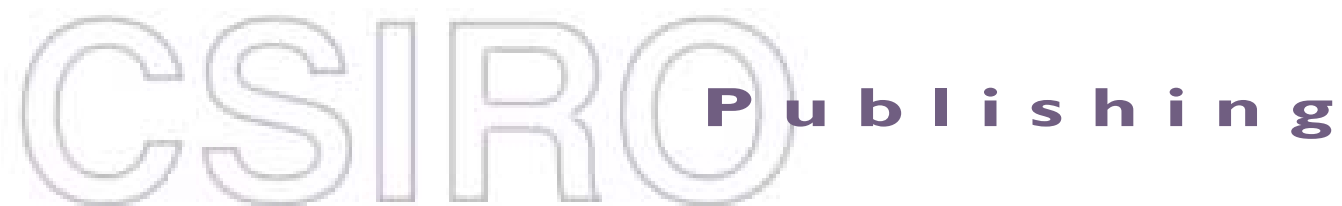

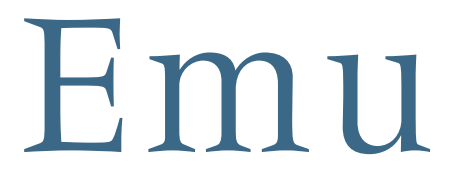

Volume 102, 2002

(c) RAOU 2002

All enquiries and manuscripts should be directed to:

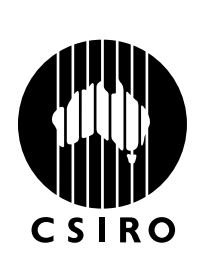

Emu

CSIRO Publishing

PO Box 1139 (150 Oxford St)

Collingwood, Vic. 3066, Australia

PUBLISHING Telephone: +61 396627622

Fax: +61396627611

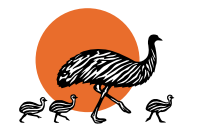

Email: publishing.emu@csiro.au

Published by CSIRO Publishing

Birds Australia for the Royal Australasian Ornithologists Union

www.publish.csiro.au/journals/emu 


\title{
Species-wide manufacture of stick-type tools by New Caledonian Crows
}

\author{
Gavin R. Hunt ${ }^{\mathrm{A}}$ and Russell D. Gray \\ Department of Psychology, University of Auckland, Auckland 92019, New Zealand. \\ ${ }^{A}$ To whom correspondence should be addressed. Email: grhunt10@hotmail.com
}

\begin{abstract}
We describe 15 additional stick-type tools collected from New Caledonian Crows since the first detailed description of these tools in 1996. All 15 tools were plant material and most were manufactured from living plants. Eleven of the tools were twigs or the midribs of leaves, one was a section of bamboo stem, and the remaining three tools were sections of fern stolon. Nine tools were hooked, including examples of two new varieties of these tools made from a thorny vine and fern stolon. The use of a diverse range of raw material to manufacture tools, and material-specific tool-making techniques further demonstrates flexibility and innovation in Crows' tool manufacture. Our findings indicate that stick-type tools are used widely by Crows and that they are used throughout the year. New Caledonian Crows join hominids and Chimpanzees as species with the flexible and widespread manufacture of sticktype tools. They join hominids as species with the widespread manufacture of distinct types of tools.
\end{abstract}

\section{Introduction}

Species-wide manufacture and use of tools is extremely rare in the animal Kingdom (Beck 1980). Reports of tool use by a species are generally based on observations from only one or several individuals (e.g. Orenstein 1972; Montevecchi 1978; Andersson 1989; Caffrey 2000). New Caledonian Crows, Corvus moneduloides (Crows hereafter), habitually use a range of tools to extract difficult-to-access prey in dead wood and in forest vegetation (Hunt 1996, 2000a). Local people throughout Grande Terre and nearby Maré Island, New Caledonia (Fig. 1), commonly tell of birds using sticktype tools in this way (GRH, personal observation). However, there are few published reports describing these tools and/or indicating where they are used by Crows (Table 1). Hunt (1996) was the first to give detailed descriptions of stick-type tools from 21 examples he collected off individual Crows that were carrying them. Fifteen of these were hooked tools manufactured at Pic Ningua and Mt Cindoa from fresh tree twigs. Manufacture was inferred from the altered nature of the twigs (e.g. bark and/or leaves removed), and from direct observation of several individuals involved in twig modification. Crows shaped the hooks on the wide ends of these tools with their bills out of adjoining stem. Hooks did not form when twigs were simply pulled off trees. The remaining six tools came from Parc Rivière Bleue (three non-hooked tools and one hooked tool) and Maré (two nonhooked tools). Five of these six tools were made from twigs, but one from Parc Rivière Bleue was a section of bamboo stem. The 21 tools were collected at various times throughout the year.

Crows are known to use stick-type tools for foraging in two main ways. One way is for extraction of large cerambycid larvae from dead wood (Hunt 2000a). The tools used for this function do not have hooks and appear to be selected then later discarded at the location-of-use. They can often be found left in open larvae burrows in dead wood or lying on the ground below them. Stick-type tools used by Pan troglodytes (McGrew et al. 1979) and Pongo pygmaeus (van Schaik and Knott 2001) are used, and can be obtained, in a similar way. The second way that Crows use tools is to search for small invertebrates in the multitude of hiding places that occur in trees and associated vegetation in forest (Hunt 1996; GRH, personal observation). Crows carry around these tools and they must be collected directly from them because they are not discarded at any easily predictable location.

In this paper we describe additional stick-type tools collected directly from New Caledonian Crows. We evaluate the implications this new information has for the distribution of Crows' stick-type tools, their variety and the diversity of raw material used.

\section{Methods}

Two of the 15 new tools described here were obtained in 1995 and 1997 , 11 were collected in 2000 during a survey of the tools that the birds manufacture from Pandanus leaves (Hunt 1996; Hunt et al. 2001) and the remaining two were obtained in 2002. Most of the 15 tools were collected incidentally from birds that we saw in the course of our research work. Eleven of them were obtained by frightening away individuals after they had either placed their tools in a secure position on their perch, transferred them from their bills to their feet when perching or placed them on the ground beside them ( 1 tool). We retrieved two tools from the ground after Crows we were observing in trees dropped them from their bills and the last two after birds left them on a feeding table. We have also collected stick-type tools from Crows at Sarraméa ( $27 \mathrm{~km}$ north-west of Nassirah; Fig. 1) since 1996, but because the birds selected or made these tools specifically to extract food placed in artificial holes we excluded them. We used 1:25000 or 1:50000 topographical maps and an altimeter to establish the approximate altitude where a tool was collected. 
Table 1. Summary of published data on stick-type tools used by New Caledonian Crows

\begin{tabular}{lllll}
\hline Site & Altitude $(\mathrm{m}$ a.s.l) & Tool material & Hooked/non-hooked tool Reference \\
\hline Nassirah & $?$ & Twig/leaf stem? & $?$ & Le Goupils $1928^{\mathrm{A}}$ \\
Parc Rivière Bleue & $?$ & Twig/leaf stem? & $?$ & Orenstein 1972 \\
South of Grande Terre & $?$ & Leaf stem? & $?$ & Orenstein 1972 \\
$?$ & $?$ & Twigs & $?$ & Hannécart and Létocart 1980 \\
Pic Ningua & $950-1300$ & Twigs & Hooked & Hunt 1996 \\
Mt Cindoa & $1100-1200$ & Twigs & Hooked & Hunt 1996 \\
Parc Rivière Bleue & $150-200$ & Twigs/bamboo & Hooked/non-hooked & Hunt 1996 \\
Maré Island & $0-100$ & Twigs & Non-hooked & Hunt 1996 \\
Sarraméa & $100-200$ & Twigs/leaf stems & Non-hooked & Hunt $2000 a$ \\
\hline
\end{tabular}

${ }^{\mathrm{A}}$ Le Goupils states that his crow observations were reported second-hand in Le Temps (1909) by Cunnisset Carnot.

\section{Results}

We collected the 15 stick-type tools at eight sites on Grande Terre and one on Maré (Table 2, Figs 1,2). The altitudes of the sites ranged from 0 to nearly $1200 \mathrm{~m}$ above sea level. Fourteen of the tools were collected from birds in rainforest or woodland away from the coast, but one (Tool $d$ ) was collected from a Crow that was using it to search in coconut, Cocos nucifera, and other trees along the beach. The tools consisted of a variety of plant material and their lengths ranged from 6.2 to $23.0 \mathrm{~cm}$ (Table 2, Fig. 2). Tools $a, b$ and $e-o$ were fresh plant material, but we do not know whether tools $c$ and $d$ were. We did not observe Crows manufacture any of the 15 tools. Tools $a, b$, and $e-o$, though, were almost certainly manufactured because they were newly removed from living vegetation. We determined an obvious working end on Tools $a, b$, and $d-o$ after examining both ends of a tool for signs of use (e.g. discolouration) and by observation of its use by a Crow (Tools $d, n$ and $o$ ), but we cannot rule out that Crows used both ends of the tools. We do not know the age or sex of the birds that carried the tools.
The three non-hooked Tools $c-e$ from Grande Terre were each made from very different material. Tool $\mathrm{c}$ was a section of bamboo stem, but not a Flagellaria indica stem like that previously described from Parc Rivière Bleue (incorrectly identified as a Greslania rivularis flower stem) (Hunt 1996). Tool $d$ was a relatively long section of midrib from a compound tree leaf. Tool $e$ was a sliver of material split from the midrib of a leaflet on a palm (Palmae) frond; we compared it with midribs on palm trees at the site. This tool was strong but flexible and spear-like in shape.

Ten of the 13 tools from Grande Terre had hooks on one end. The shapes of hooked-twig Tools $a$ and $g-j$ closely resembled those described previously from Mt Cindoa and Pic Ningua (Hunt 1996). Tool $a$ was made from Elaeocarpus dognyensis, like most of the stick-type tools collected at Pic Ningua. Tool $g$ also appeared to be manufactured from Elaeocarpus, but we do not know which tree species Tools $h-j$ were made from. Tools $f$ and $m$ were manufactured from the midribs of compound leaves, probably those of the thorny vine Caesalpinia schlechteri, which resulted in novel

Table 2. Data on 15 new stick-type tools collected from New Caledonian Crows

The tools are shown in Fig. 2. Dried tool-length is measured on a straight line between both ends of a tool

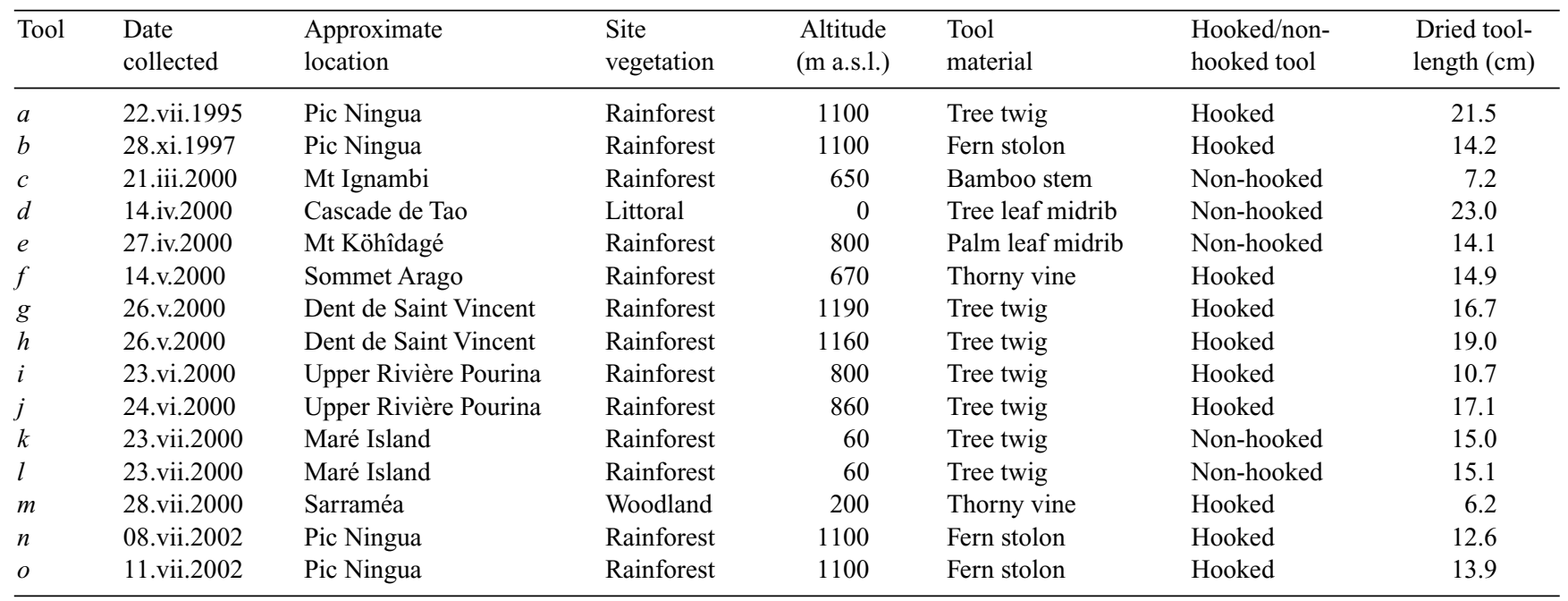




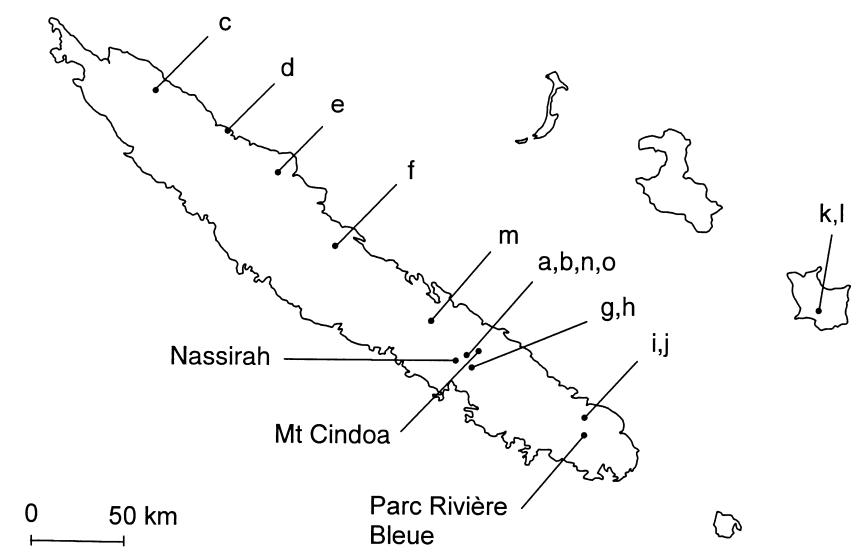

Fig. 1. The main islands of New Caledonia, showing the approximate locations on Grande Terre and Mare (far right) where we collected the 15 stick-type tools from Crows. Letters indicating locations match the respective letters for individual tools in Table 2. Mt Cindoa and Parc Rivière Bleue are the other locations on Grande Terre where Hunt (1996) collected stick-type tools from Crows (see Table 1).

hooking instruments: single, strong, rose-like thorns formed the hooks at the tips of the working ends of the tools. Tools $b, n$ and $o$ were made from stolons of Nephrolepis fern. They had hooks at the working ends. These were formed by obvious cuts to main runners just below short sections of side-branching. It was difficult to tell whether the sidebranching that formed the hooks had also been cut, but short lateral extensions commonly occur naturally on stolons (GRH, personal observation).

Non-hooked Tools $k$ and $l$ from Maré closely resembled the two collected there previously in the southern region of the island (Hunt 1996). They were twigs pulled off branches and their tips or narrow ends appeared to be the working ends.

\section{Discussion}

Our results show that the phenomenon of the species-wide manufacture of stick-type tools in the wild is not restricted to hominids, Homo spp., and Chimpanzees as previously thought (e.g. van Schaik et al. 1999). Similarly, flexible tool manufacture is not restricted to hominids, Chimpanzees and Orangutans, as has been stated (Fox et al. 1999). We found that manufacture of stick-type tools by the Crows is widespread in New Caledonia and that birds use a range of raw material and material-specific techniques to make these tools. These tools have now been collected from birds at a range of altitudes and in most months of the year. The frequency with which crows use these tools is unknown, however. At all but two of the sites where stick-type tools have

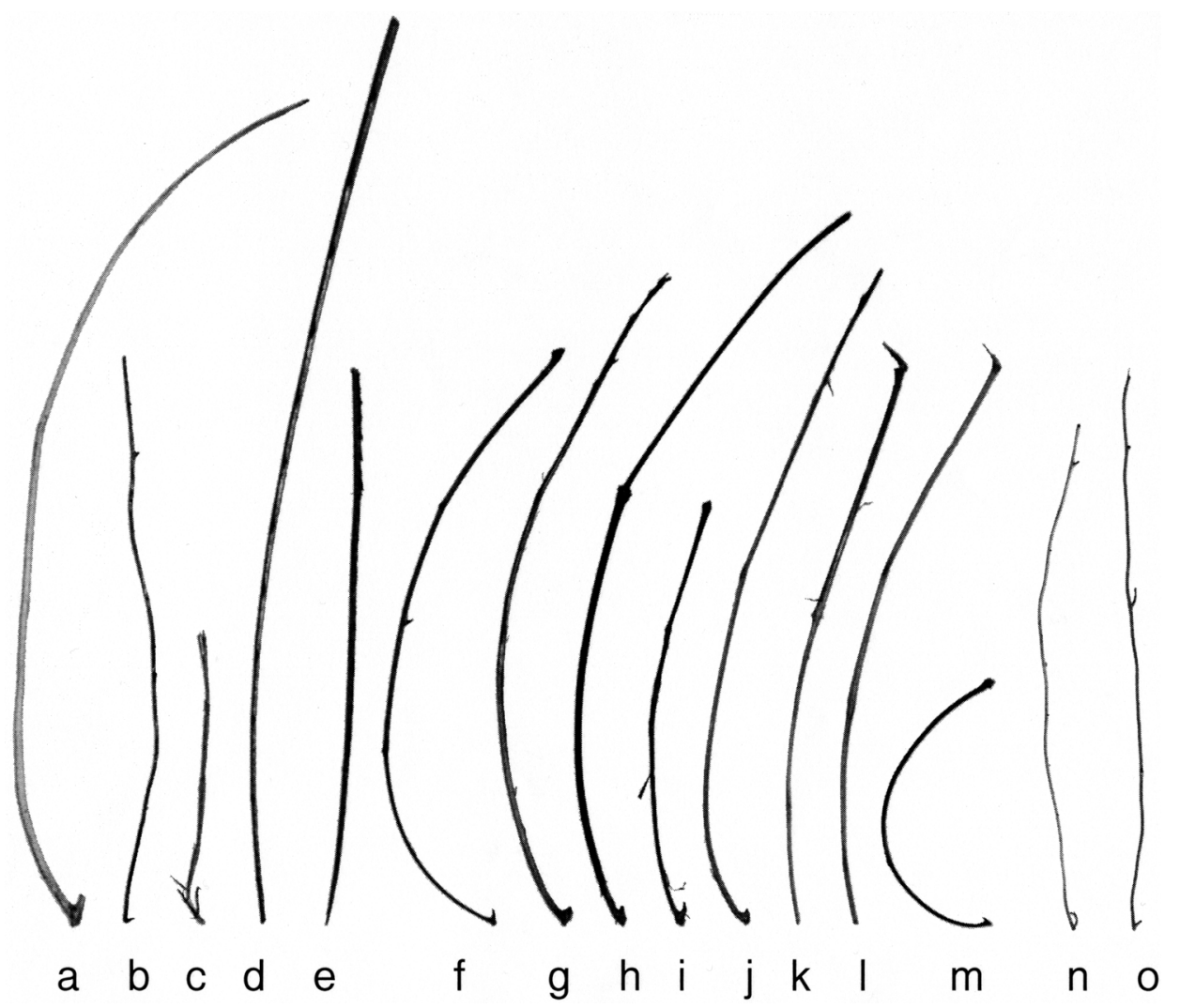

Fig. 2. Fifteen new stick-type tools collected from Crows on Grande Terre $(a-j$ and $m-o)$ and Maré $(k$ and $l)$. The evident working ends (see text) of Tools $a, b$, and $d-o$ are at bottom, but we could not identify a working end on Tool $c$. The lengths of the tools are given in Table 2 . 
been collected, Crows commonly manufacture pandanus tools (Hunt et al. 2001), which we have also collected from birds in most months (February to September) of the year (Hunt 1996; our unpublished data). Therefore Crows join hominids in an exclusive group of species with the widespread manufacture of distinct types of tools.

The four new sites where Crows manufacture hookedtwig tools add to the three already known (Table 1). The use of these hooked tools may be widespread, at least in the southern half of Grande Terre. The wide, hooked ends were used as working ends on all hooked-twig tools collected here and previously (Hunt 1996). The wide ends appeared to be the working ends on the non-hooked tools collected in Parc Rivière Bleue (Hunt 1996). In contrast, the narrow ends appeared to be the working ends on non-hooked Tools $d$ and $e$ from Grande Terre and $k$ and $l$ from Mare in this study. Reexamination of the two tools that Hunt (1996) collected on Maré suggests that the narrow ends (not the stated wide ends) were also the working ends.

New Caledonian Crows appear to be the only non-human species that manufacture and use hooked instruments. This capability has also been attributed to Chimpanzees (Boesch 1996), on the basis of Sugiyama and Koman's (1979) description of 'branch-hauling' by one Chimpanzee in Guinea. Since Boesch's claim, several authors have stated that Chimpanzees use hook tools (Boesch and Tomasello 1998; van Schaik et al. 1999; Woolfson 2000; Ambrose 2001). However, a careful reading of Sugiyama and Koman's paper does not support Boesch's interpretation (see Hunt $2000 b$ ). Sugiyama and Koman described how three individuals prepared and used sticks to try to obtain ripe figs from an out-of-reach branch above them. They used sticks with and without hook-like side branching in their attempts. The former were used by only one male. On two of the four occasions that he did so he held the stick at the wrong end to use as a hook tool. The authors concluded that '.. . [the chimpanzees] failed to make an effective hook-type stick-tool. However, if they had succeeded ... they would readily have pulled and captured the hanging fig branch. This must show the limit of the chimpanzees' tool-making ability ...'. Independent experiments with captive animals (Nagel et al. 1993; Povinelli 2000) support Sugiyama and Koman's conclusion that Chimpanzees have little understanding of the functionality of hooks.

The hooked-vine tools $(f$ and $m$ ) and the fern stolon tools $(b, n$ and $o$ ) appear to be two new varieties of hooked tool. Hooks on twig tools are formed by crows using their bills to shape them out of adjoining stem. However, it was only necessary for birds to modify compound vine leaves in such a way as to make use of 'ready-made' hooks (thorns) on the leaf midribs. Two strategically made cuts to a main runner were all that seemed to be required to create hooked tools out of fern stolons. Crows therefore use appropriate techniques to make hooked tools out of quite different materials. This flexibility and innovation in tool manufacture by Crows allows them to construct a similar functional product from a range of materials and thus suggests that their tool-making is goal-directed.

The palm midrib tool $(e)$ also points to flexibility and innovation in the use of plant material and in the techniques of tool manufacture. The slice of midrib little resembles a palm leaflet because it is a thin slither of material that has been removed from a larger section of vegetation. It was not simply broken off like a twig; therefore, its manufacture probably required a novel technique. GRH was told by a local person (Hatanasse Salo, personal communication) in 1993 that Crows made such tools on Maré from the midribs of leaflets on the fronds of coconut trees, but this has not been confirmed.

Tool material used by Chimpanzees is generally found to be closely associated with available resources at the site (McGrew 1992). For example, Chimpanzees make most of their termiting tools from plants close to the termite nests (McGrew et al. 1979; Boesch and Boesch 1990). Crows that extracted cerambycid larvae from dead wood at an experimental site also obtained their tools within a few metres of prey (Hunt 2000a). The variety of plants used for the tools we described here may simply be a function of the resources at hand when birds decided to procure tools, although Crows appear to have a strong preference for the use of E. dognyensis trees at Pic Ningua (Hunt 1996). The use of hooked tools, though, is clearly related to Crow behaviour and is not merely an incidental consequence of available resources because manufacture of hooked-tools requires material-specific techniques. Why some crows used hooked tools and others used non-hooked tools is unknown. Possible reasons for this difference might lie in differences in ecological factors like prey type or prey-extraction sites or different social learning traditions. A challenge for future research is to determine the cognitive, behavioural and ecological underpinnings of the considerable local and geographic variation in tools made by New Caledonian Crows.

\section{Acknowledgments}

We thank Thierry Chaverot (Ressources Naturelles, Province Sud), Christophe Lambert (Service des Parcs et Réserves Terrestres, Province Sud), Christian Papineau (Service Forêt-Bois-Environnement, Province Nord) and Chantal Giraudon (Service Topographique et des Ressources Naturelles, Province des Iles Loyauté) for permission to work in New Caledonia. We are grateful to Etienne DuTailly for reference material and accommodation and use of communications facilities in New Caledonia, John Braggins for identification of tool material, Tanguy Jaffré for help with identification of the vine, and Carolee Caffrey for helpful comments on the manuscript. 


\section{References}

Ambrose, S. H. (2001). Paleolithic technology and human evolution. Science 291, 1748-1753.

Andersson, S. (1989). Tool use by the fan-tailed raven (Corvus rhipidurus). Condor 91, 999.

Beck, B. (1980). 'Animal Tool Behaviour: the Use and Manufacture of Tools by Animals.' (Garland: New York.)

Boesch, C. (1996). The question of culture. Nature 379, 207-208.

Boesch, C., and Boesch, H. (1990). Tool use and tool making in wild chimpanzees. Folia Primatologica 54, 86-89.

Boesch, C., and Tomasello, M. (1998). Chimpanzee and human cultures. Current Anthropology 39, 591-614.

Caffrey, C. (2000). Tool modification and use by an American crow. Wilson Bulletin 112, 283-284.

Fox, E. A., Sitompul, A. F., and van Schaik, C. P. (1999). Intelligent tool use in wild Sumatran orangutans. In 'The Mentality of Gorillas and Orangutans'. (Eds S. T. Parker, H. L. Miles and R. W. Mitchel.) pp. 99-116. (Cambridge University Press: Cambridge.)

Le Goupils, M. (1928). 'Dans la Brousse Calédonienne: Souvenirs d'un Ancien Planteur 1898-1904.' (Perrin: Paris.)

Hannécart, F., and Létocart, Y. (1980). 'Oiseaux de Nouvelle Calédonie et des Loyautes. Vol. I.' (Les Editions Cardinalis: Nouméa, New Caledonia.)

Hunt, G. R. (1996). Manufacture and use of hook-tools by New Caledonian crows. Nature 379, 249-251.

Hunt, G. R. (2000a). Tool use by the New Caledonian crow Corvus moneduloides to obtain Cerambycidae from dead wood. Emu 100, $109-114$.

Hunt, G. R. (2000b). Human-like, population-level specialization in the manufacture of pandanus-tools by New Caledonian crows Corvus moneduloides. Proceedings of the Royal Society, London B 267, 403-413.
Hunt, G. R., Corballis, M. C., and Gray, R. D. (2001). Laterality in tool manufacture by crows. Nature 414, 707 .

McGrew, W. C. (1992). 'Chimpanzee Material Culture: Implications for Human Evolution.' (Cambridge University Press: Cambridge.)

McGrew, W. C., Tutin, C. E. G., and Baldwin, P. J. (1979). Chimpanzees, tools, and termites: cross-cultural comparisons of Senegal, Tanzania, and Rio Muni. Man 14, 185-214.

Montevecchi, W. A. (1978). Corvids using objects to displace gulls from nests. Condor 80, 349.

Nagel, K., Olguin, R. S., and Tomasello, M. (1993). Processes of social learning in the tool use of chimpanzees (Pan troglodytes) and human children (Homo sapiens). Journal of Comparative Psychology 107, 174-186.

Orenstein, R. I. (1972). Tool-use by the New Caledonian crow (Corvus moneduloides). Auk 89, 674-676.

Povinelli, D. J. (2000). 'Folk Physics for Apes: the Chimpanzee's Theory of How the World Works.' (Oxford University Press: Oxford.)

Sugiyama, Y., and Koman, J. (1979). Tool-using and -making behavior in wild chimpanzees at Bossou, Guinea. Primates 20, 513-524.

van Schaik, C. P., and Knott, C. D. (2001). Geographic variation in tool use on Neesia fruits in orangutans. American Journal of Physical Anthropology 114, 331-342.

van Schaik, C. P., Deaner, R. O., and Merrill, M. Y. (1999). The conditions for tool use in primates: implications for the evolution of material culture. Journal of Human Evolution 36, 719-741.

Woolfson, A. (2000). 'Life without Genes.' (HarperCollins: London.)

Manuscript received 1 October 2001, accepted 10 July 2002 